\title{
Experimental and chemometric studies of cell membrane permeability
}

\author{
Yong Liu ${ }^{\mathrm{a}, \mathrm{b}}$, Tao Ran ${ }^{\mathrm{a}}$, Esvieta Tenorio-Borroto ${ }^{\mathrm{e}}$, Shaoxun Tang ${ }^{\mathrm{a}}$, Alejandro Pazos ${ }^{\mathrm{b}}$, \\ Zhiliang Tan ${ }^{\mathrm{a}}$, Humberto González-Díaz ${ }^{\mathrm{c}, \mathrm{d}}$ \\ ${ }^{a}$ Key Laboratory of Subtropical Agro-ecological Engineering, Institute of Subtropical Agriculture, Chinese Academy \\ of Sciences (CAS), Changsha, Hunan 410125, PR China \\ ${ }^{b}$ Computer Sciences Faculty, University of A Coruna, Campus de Elviña s/n, A Coruña, 15071 A Coruña, Spain \\ ${ }^{c}$ Department of Organic Chemistry II, University of the Basque Country UPV/EHU, 48940 Leioa, Spain \\ ${ }^{d}$ IKERBASQUE, Basque Foundation for Science, 48011 Bilbao, Spain \\ ${ }^{e}$ Faculty of Veterinary Medicine and Animal Science, Autonomous University of the State of Mexico, Toluca 50090, \\ Mexico
}

\begin{abstract}
Cell membrane permeability $(\mathrm{P})$ governs the molecules or ions to transport through the cell membrane. In this study, we measured $\mathrm{P}$ of ruminal microbes in different initial levels of surface tension (ST) and specific surface area (SSA). Data of $\mathrm{P}$ in present study and published data of $\mathrm{pH}$, ammonia concentration, digestibility of neutral detergent fibre and gas production in two time scales $\left(t_{k}\right.$ and $\left.t_{k}\right)$ as input variables $V_{q}\left(t_{k}\right)$ were took into consideration for developing a predictive model. The ideas of Box-Jenkins Operators and Covariance Perturbation Theory Operators were used for the first time to establish a model to predict the variations of cellular permeability. The best model presented sensitivity, specificity and accuracy of $>0.89$, and MCC $>0.78$ for 77,781 cases (training + validation series). In addition, we also reported a simulation of ternary phase diagram with predicted values of cell permeability at various experimental conditions.
\end{abstract}

Keywords

Cell membrane permeability; Moving average; Covariance; Perturbation Theory; Predictive model

\section{Introduction}

Cell membrane surface properties are vital to the metabolism or dynamic processes for surviving organisms like cell membrane permeability, fluidity, hydrophobicity, etc. Cell membrane permeability (P) plays an important role in governing the molecules or ions to transport through cell membrane [1]. In addition, the cell membrane is more permeable to uncharged or hydrophobicity compounds and less permeable to polar or charged compounds [2], [3] and [4]. Among the charged compounds, negative compounds tend to have much higher permeability than the positive ones. $\mathrm{P}$ might depend on the compositions of cell membrane, environmental conditions (pressure, concentration, temperature or surface tension), and the properties of solute.

The physicochemical characteristics of medium or substrate, such as surface tension (ST) and specific surface area (SSA), were considered as key factors influencing on cell membrane permeability [5] and [6]. Surfactants and metabolites have been proved to influence ST [7] and [8]. ST has been proved to change hydrophilic pore structure in lipid layers [9]. On the other hand, SSA could directly influence the microbial metabolism processes and adhesion ability [10]. However, there are few works that report the combinatorial influence of ST and SSA over cell membrane permeability of ruminal microbes. Our previous work showed that $\mathrm{P}$ values change with the ST of medium and SSA of material by ruminal mimic in vitro fermentation. In our previous work, we had also reported the effects of ST and SSA on gas production $\left(\mathrm{V}_{\mathrm{g}}\right), \mathrm{pH}$ values, and ammonia concentration $\left(\mathrm{c}\left(\mathrm{NH}_{3}\right)\right)$ [10]. In principle, we can use all the 
datasets obtained on these works to develop a general predictive model for $\mathrm{P}$ as a function of media physicochemical properties and experimental conditions. However, we carried out the experiments and measured all variables in two different time scales $\left(t_{k}\right.$ and ' $\left.t_{k}\right)$.

Covariance provides a measure of the strength of the similarity between two or more sets of random variables. Cross-covariance is the analogue of covariance when the variables have been measured on different time scales. In other words, if the greater value of one variable is corresponding to the greater value of the other variable, i.e., the variable tends to show similar behaviour, the covariance is positive [11]. In recently years, covariance or cross-covariance is a hot research subject in biological field. Li et al. [12], measured the strength of the correlations between neuron pairs using cross-covariance to show dynamic changes over time. Xiao et al. [13], developed iNR-PhysChem: a sequence-based predictor for identifying nuclear receptors and their subfamilies using cross-covariance transformations. Doytchinova et al. [14], developed a new alignment-free approach for antigen prediction based on auto-cross covariance transformation and based on protein sequences. Liu et al. [15], proposed a method for protein remote homology detection using auto-cross covariance transformation. In addition, chemometric [16] and experimental approaches are widely combined to use in the research field of biology [17], and metabolism process [18] and [19].

Perturbation Theory (PT) methods start with a known exact solution of a problem by adding corrections due to the variations of different experimental conditions $\left(c_{j}\right)$. In general, the outputs of the model are functions $f\left(\varepsilon_{i}\right)$ of one variable $\left(\varepsilon_{i}\right)$ or property of the system under a given set of conditions $\left(c_{j}\right)$ [20]. We have proposed to use Box-Jenkins Operators (BJOs) to measure the deviation of the values of different input variables $\left({ }^{i} \mathrm{~V}_{\mathrm{p}}\right)$ in PT models of molecular biosystems [21], [22], [23] and [24], including fatty acid metabolism and distribution on rumen microbes [19] and [25]. In a very recent work, we also introduced Covariance Perturbation Theory Operators (CPTOs) to predict the properties of molecular biosystems like binary micelle nanoparticles [26].

In the present work, we propose a new method for the prediction of cell membrane permeability of ruminal microbes based on the methods mentioned before. So, the covariance BJO/CPTOs were set as input variables but using dual time scales for the first time. The best Covariance Perturbation Theory (CPT) model found predicted the effects of $>$ 77,000 perturbations in experimental conditions over cell membrane permeability of ruminal microbes. Accordingly, our new CPT model might provide an opportunity to investigate the effect of perturbations on cell membrane permeability of ruminal microbes involved in vitro fermentation variables.

\section{Materials and methods}

\subsection{Experimental section}

The experimental was conducted to investigate the variations of cell membrane permeability under various initial combinatorial conditions of ST and SSA. In doing so, 12 different combinatorial conditions of ST and SSA (4 ST $\times 3 \mathrm{SSA}$ ) were implemented in vitro fermentation system. In addition, each combination was conducted in 3 individual runs with 3 replicates each. In this study, the first factor (ST) was composited of 4 levels $(36,43,46$, and $54 \mathrm{mN} / \mathrm{m})$, whereas, the second factor (SSA) composited of 3 levels $\left(3.27,3.73\right.$, and $\left.4.44 \mathrm{~m}^{2} / \mathrm{g}\right)$. The details see the following steps.

\subsubsection{Experimental animal}

The experiment and experimental animal use were approved by the Animal Care Committee, Institute of Subtropical Agriculture, the Chinese Academy of Sciences, Changsha, China. Three ruminal fistulae Liuyang black wether goats (average $\mathrm{BW} \pm \mathrm{SD} ; 25.0 \pm 4.5 \mathrm{~kg}$ ) were set as fluid donor animals. The goats were fed with a total mixed rations consisted of maize stover and concentrated in a ratio of 40:60 (w/w) for $650 \mathrm{~g} / \mathrm{d}$. For the concentrate ingredients see our previous work [10].

\subsubsection{Surface tension factor}

The ST gradients of the inoculum were altered by adding the non-ionic surfactant alkyl polyglucoside (APG; Hunan Diyuan Co., Ltd., China). The APG was added in a concentration of 0, 0.02, 0.05 and $0.12 \%(\mathrm{v} / \mathrm{v})$ to each flask of inoculum. The ST of the inoculum with buffer was measured immediately by a tensiometer with model K100 (KRÜSS GmbH, Germany) [27]. The responding ST was 54, 46, 43 and $36 \mathrm{mN} / \mathrm{m}$, respectively. 


\subsubsection{Specific surface area factor}

A sample of rice straw containing $630 \mathrm{~g} / \mathrm{kg}$ dry matter of neutral detergent fibre (NDF) was obtained from rice straw. The NDF was extracted from rice straw without using sodium sulfite or amylase addition described by Van Soest et al. [28]. The dried NDF was ground through three screens $(0.15,0.25$ and $0.84 \mathrm{~mm}$ ) using a grinder (DF-2, Changsha Instrument Factory, Changsha, China) to obtain three different particle sizes. The screen sizes were chosen to represent the known particle distribution of digest particles in the rumen of small ruminants [29], [30] and [31]. A representative sample of each particle size was used to measure and calculate its SSA. The measurement of SSA was performed in duplicate with the procedure of Brunauer-Emmett-Teller [32] by a Surface Area Analyzer (Quadrasorb-SI, Quantachrome Inc., Florida, CA, USA).

\subsubsection{In vitro fermentation technique and sample collecting}

Rumen fluid was obtained from 3 goats, appropriate equal amount from each, approximately $1 \mathrm{~h}$ before the morning feeding, pooled, and strained through 4 layers of cheesecloth into a flask and flushed with oxygen-free $\mathrm{CO}_{2}$. This process was aimed to retain ruminal microbes but remove the feed particle. Rumen fluid was transported in insulated flasks to the laboratory within $30 \mathrm{~min}$ of collection. The rumen fluid was transferred to four flasks and buffer medium was added in a ratio of 1:2 ratio ( $\mathrm{v} / \mathrm{v}$, rumen fluid:buffer medium) under continuous flushing with $\mathrm{CO}_{2}$. The buffer medium compositions were according to the description of Tang et al. [33].

In vitro incubations were performed according to Tang et al. [34]. Appropriate NDF sample $(500 \pm 50 \mathrm{mg})$ was accurately weighed into a screw-cap serum bottle (145 mL volume) and flushed with $\mathrm{CO}_{2}$. Three replicate vials were prepared for each treatment for each end-point measurement time $(6,12$, 24,48 and $72 \mathrm{~h}$ ). Inoculum with the appropriate conditions of ST $(50 \mathrm{~mL})$ was added, bottles were sealed with rubber stoppers and then gently shaken and incubated at $39^{\circ} \mathrm{C}$ in an incubator. The in vitro fermentation was separately run three times on different days to collect the mixed rumen fluid, so that each treatment was conducted in triplicate.

The inoculum sample (fermentation supernatant) for determining cell membrane permeability was collected from each fermented bottle. Briefly, $10 \mathrm{~mL}$ of supernatant from each bottle was centrifuged at $500 \times \mathrm{rpm}$ at $4{ }^{\circ} \mathrm{C}$ for $10 \mathrm{~min}$ to remove the feed particles. The supernatant was then further centrifuged at $5000 \times \mathrm{rpm}$ and $4{ }^{\circ} \mathrm{C}$ for $10 \mathrm{~min}$. The supernatant $(3 \mathrm{~mL})$ was used to be carried out from the cell membrane permeability assay.

\subsubsection{Cell membrane permeability assay}

The $\mathrm{P}$ value of rumen microbiome was measured according to the fluorescence method of fluorescein-isothiocyanate to dextrans (FITC-Dextran, Sigma, molecular weight $\approx 38 \mathrm{kDa}$ ) [35]. Briefly, the mixture $\left(\mathrm{A}_{0}\right.$, the initial concentration of FITC-Dextran in media) of $1 \mathrm{~mL}$ FITC-Dextran solution $(100 \mathrm{mg} / \mathrm{L})$ was added to a $3 \mathrm{~mL}$ supernatant from the incubation bottle, and incubated at $37^{\circ} \mathrm{C}$ in darkness for $1 \mathrm{~h}$. Then a subsample of $2 \mathrm{~mL}$ was centrifuged under anaerobic conditions at $10,000 \times g$ and $4{ }^{\circ} \mathrm{C}$ for $10 \mathrm{~min}$ and $1.5 \mathrm{~mL}$ supernatant $\left(\mathrm{A}_{1}\right.$, the final concentration of FITC-Dextran in media) was measured using a fluorospectrophotometer (excitation wavelength $488 \mathrm{~nm}$, emission wavelength $520 \mathrm{~nm}$ ). Blanks were prepared to account for any non-specific effects of the rumen inoculum using $5 \mathrm{~mL}$ of the incubation inoculum from each bottle. The inoculum was centrifuged at $10,000 \times g$ and $4{ }^{\circ} \mathrm{C}$ for $10 \mathrm{~min}$, $3 \mathrm{~mL}$ of supernatant was obtained, and $1 \mathrm{~mL}$ of distilled water was added. After homogenization the absorbance was measured under the same condition as described above. The permeability value (expressed as $\mathrm{P}_{\mathrm{ij}}(\%)$ or $\mathrm{P}_{\mathrm{ij}}$ ) was calculated as the following equation.

$$
P_{i j}(\%)=100 \times \frac{A_{0}-A_{1}}{A_{0}} .
$$




\subsection{Dataset}

The dataset comes from two different sources, results of cellular permeability presented here and data of experimental parameters published by Liu et al. [10]. In these papers we studied the combinatorial effects of four levels of ST $=54,46,43$ and $36 \mathrm{mN} / \mathrm{m}$ with three levels of SSA $=3.27,3.73$ and $4.44 \mathrm{~m}^{2} / \mathrm{g}$ on fermentation performance with two different parts of experiment. However, there are two important differences between these two parts of experiment. The first difference was that in one part we measured mimic fermentation variables like $\mathrm{pH}, \mathrm{c}\left(\mathrm{NH}_{3}\right)$, and digestibility (D). In the other part, we measured gas production $\left(\mathrm{V}_{\mathrm{g}}\right)$ in vitro fermentation micro-ecosystem under the same conditions.

Another important difference was the scale of time used (sampling frequency). In fact, two time series were used in experiments. The time series of $\mathrm{P}_{\mathrm{ij}}$ sampling (frequency over time) used in this work was $\mathrm{t}_{\mathrm{k}}=6,12,24,36,48$, and $72 \mathrm{~h}$. This time series coincided the one used to measure $\mathrm{pH}, \mathrm{c}\left(\mathrm{NH}_{3}\right)$, and $\mathrm{D}$. However, the second time series used to measure $\mathrm{V}_{\mathrm{g}}$ sampling was ' $\mathrm{t}_{\mathrm{k}}=1,2,3,4,6,8,12,16,20,24,28$, 32, 36, 40, 48, 52, 56, 58, 62, 68 and 72 h. In Fig. 1, it shows that the details of experimental section of present work and previous published work for providing the dataset to develop a prediction CPT model. The full dataset of present work was published on the website of Figshare with Doi: doi.org/10.6084/m9.figshare.1591840[36].

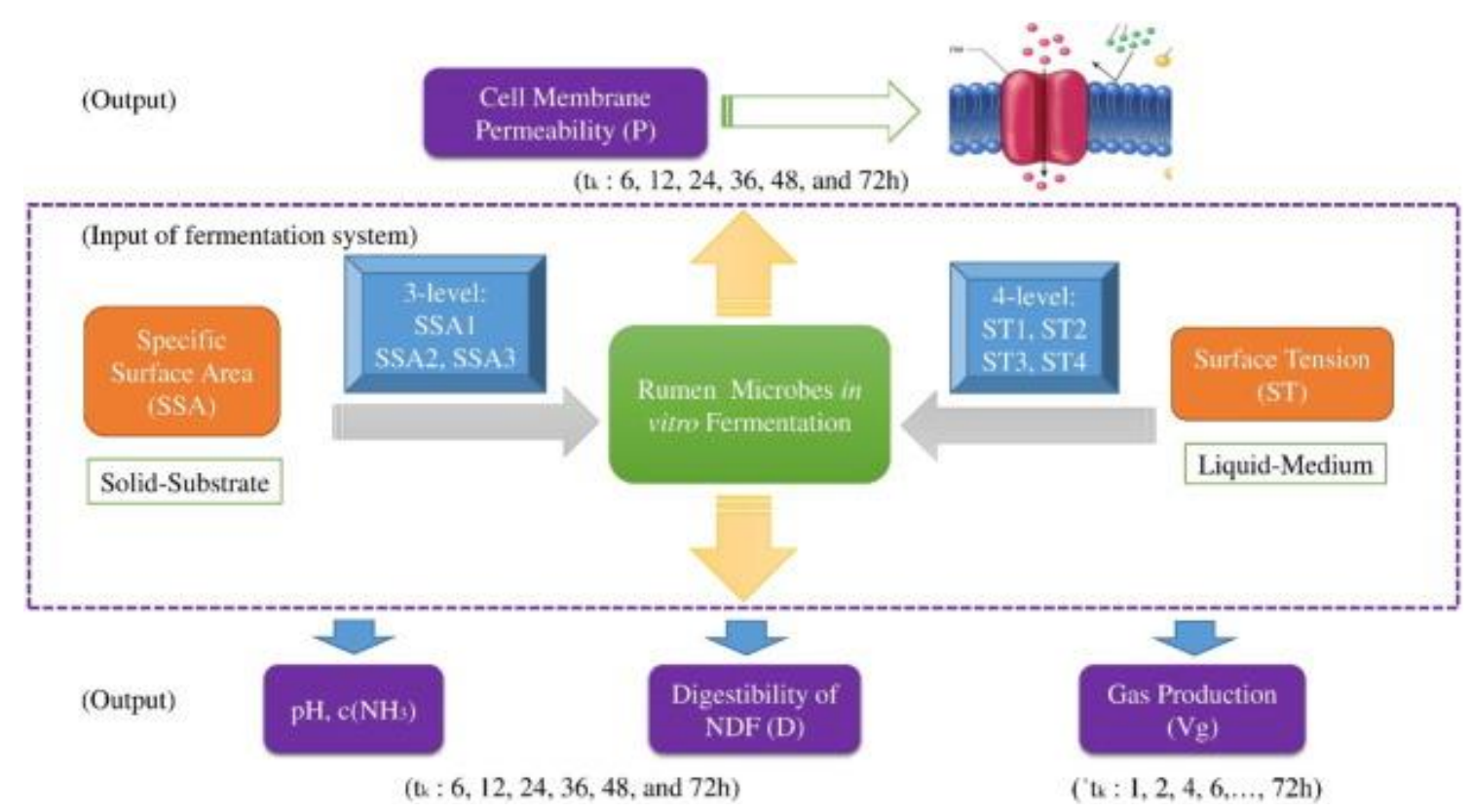

Fig. 1. Flow chart of experimental section for constructing the dataset used in present work.

\subsection{Computational model}

In this work we want to develop a model for the variation of cellular permeability $\left(\Delta \mathrm{P}_{\mathrm{ij}}\right)$ in fermentation as a function of different experimental variables like $\mathrm{pH}, \mathrm{c}\left(\mathrm{NH}_{3}\right), \mathrm{D}$, and $\mathrm{V}_{\mathrm{g}}$. We denoted these variables $\mathrm{V}_{\mathrm{q}}\left(\mathrm{t}_{\mathrm{k}}\right)$. The subscript ${ }_{\mathrm{q}}$ indicates the type of variable and $\mathrm{t}_{\mathrm{k}}$ indicates that the variables change over time. However, it is probable that $\Delta \mathrm{P}_{\mathrm{ij}}$ depends not only on the additive effect of each variable $\mathrm{V}_{\mathrm{q}}\left(\mathrm{t}_{\mathrm{k}}\right)$ but also on the interaction among some of them. In addition, as the degree of variability in fermentation experiment used to be high, we decided to incorporate terms to measure deviations of data from the expected values (data dispersion). Moreover, as we mentioned in the previous section, these variables have been measured on two different time scales $t_{k}$ and ${ }^{\prime} t_{k}$. Consequently, we decided to fit a model based on the following types of terms.

a) Single variables $\mathrm{V}_{\mathrm{q}}\left(\mathrm{t}_{\mathrm{k}}\right)$ to account for the additive effect of one variable alone.

b) Cross-product of single variables $\mathrm{V}_{\mathrm{q}}\left(\mathrm{t}_{\mathrm{k}}\right) \cdot \mathrm{V}_{\mathrm{q}}\left(\mathrm{t}_{\mathrm{k}}\right)$ for direct interaction among variables.

c) Moving average terms $\Delta \mathrm{V}_{\mathrm{q}}\left(\mathrm{t}_{\mathrm{k}}\right)=\mathrm{V}_{\mathrm{q}}\left(\mathrm{t}_{\mathrm{k}}\right)-<\mathrm{V}_{\mathrm{q}}\left(\mathrm{t}_{\mathrm{k}}\right)>$ to account for variable dispersion. In these terms $\left\langle\mathrm{V}_{\mathrm{q}}\left(\mathrm{t}_{\mathrm{k}}\right)\right\rangle$ is the average of the variable ${ }_{\mathrm{q}}$ in the same experimental condition [20] and [25]. 
d) We also incorporate the effect of interactions between these terms and original variables $\mathrm{V}_{\mathrm{q}}\left(\mathrm{t}_{\mathrm{k}}\right) \cdot \Delta \mathrm{V}_{\mathrm{q}}\left(\mathrm{t}_{\mathrm{k}}\right)$ to account for the interaction of dispersion in one variable with respect to others.

e) Covariance terms $\Delta \mathrm{V}_{\mathrm{q}}\left(\mathrm{t}_{\mathrm{k}}\right) \cdot \Delta \mathrm{V}_{\mathrm{q}}\left(\mathrm{t}_{\mathrm{k}}\right)$ to account for the covariance of two variables at the same time.

f) Cross-covariance terms $\Delta \mathrm{V}_{\mathrm{q}}\left(\mathrm{t}_{\mathrm{k}}\right) \cdot \Delta \mathrm{V}_{\mathrm{i}_{\mathrm{q}}}\left(\mathrm{t}_{\mathrm{k}}\right)$ to account for the covariance of two variables measured in two different time scales [37].

The model is one linear additive model of all the terms mentioned above. These terms were added as corrections to the expected value of cell permeability $\left(\mathrm{P}_{\mathrm{ij}}\right)$. Therefore, the first input variable ${ }^{1} f\left(\mathrm{P}_{\mathrm{j}}\right.$, $\left.t_{k}\right)_{\text {expt }}=P\left(t_{k}\right)=P_{\text {expt }} \cdot t_{k}$, refers to expected cell membrane permeability values calculated as the variation on different time scales. Among, $\mathrm{P}_{\text {expt }}$ refers to the expected cell permeability values. In this sense, the model resembles to a CPT model with terms similar to those used by ARIMA models of Box and Jenkins Operator for Time Series Analysis [38]. The general formula of the model proposed is the following:

$$
\begin{aligned}
& { }^{0} \mathrm{f}\left(\mathrm{P}_{\mathrm{ij}}\right)_{\text {pred }}=\mathrm{a}_{0}+{ }^{1} \mathrm{f}\left(\mathrm{P}_{\mathrm{ij}}, \mathrm{t}_{\mathrm{k}}\right)_{\text {expt }}+\sum_{\mathrm{q}=1}^{\mathrm{q}=\mathrm{q}_{\max }} \mathrm{a}_{\mathrm{q}} \cdot \mathrm{V}_{\mathrm{q}}\left(\mathrm{t}_{\mathrm{k}}\right)+\sum_{\mathrm{q}=1, \prime \mathrm{q}=1}^{\mathrm{q}=\mathrm{q}_{\max }, \mathrm{q}={ }^{\prime} \mathrm{q} \max } \mathrm{a}_{\mathrm{q},{ }^{\prime} \mathrm{q}} \cdot \mathrm{V}_{\mathrm{q}}\left(\mathrm{t}_{\mathrm{k}}\right) \cdot \mathrm{V}_{\prime \mathrm{q}}\left({ }^{\prime} \mathrm{t}_{\mathrm{k}}\right) \\
& +\sum_{\mathrm{q}=1, \prime \mathrm{q}=1}^{\mathrm{q}=\mathrm{q}_{\max }, \mathrm{q}=\prime \mathrm{q}_{\max }} \mathrm{a}_{\mathrm{q}} \cdot \Delta \mathrm{V}_{\prime \mathrm{q}}\left(\mathrm{t}_{\mathrm{k}}\right)+\sum_{\mathrm{q}=1, \mathrm{q}^{\prime}=1}^{\mathrm{q}=\mathrm{q}_{\max }, \mathrm{q}=\prime \mathrm{q}_{\max }} \mathrm{a}_{\mathrm{q}, \mathrm{q}^{\prime}} \cdot \Delta \mathrm{V}_{\mathrm{q}}\left(\mathrm{t}_{\mathrm{k}}\right) \cdot \Delta \mathrm{V}_{\prime \mathrm{q}}\left({ }^{\prime} \mathrm{t}_{\mathrm{k}}\right) \\
& +\sum_{\mathrm{q}=1, \prime \mathrm{q}=1}^{\mathrm{q}=\mathrm{q}_{\max }, \mathrm{q}^{\prime}=\prime \mathrm{q}_{\max }} \mathrm{a}_{\mathrm{q}, \mathrm{q}} \cdot \mathrm{V}_{\mathrm{q}}\left(\mathrm{t}_{\mathrm{k}}\right) \cdot \Delta \mathrm{V}_{\prime \mathrm{q}}\left({ }^{\prime} \mathrm{t}_{\mathrm{k}}\right)
\end{aligned}
$$

We can try to seek this model using a regression method. However, as our aim was to detect the changes in $\mathrm{P}_{\mathrm{ij}}$ we decided to carry out a classification analysis. For this we calculated the variable $\Delta \mathrm{P}_{\mathrm{ij}}$ to measure the changes on cellular permeability from experimental values using a cut-off. In this sense, $\Delta \mathrm{P}_{\mathrm{ij}}=1$ when $\left.\mathrm{P}_{\mathrm{ij}}\right\rangle\left\langle\mathrm{P}_{\mathrm{ij}}\right\rangle\left(\mathrm{P}_{\mathrm{ij}}\right.$ higher than average $\left.\left\langle\mathrm{P}_{\mathrm{ij}}\right\rangle\right)$ or $\Delta \mathrm{P}_{\mathrm{ij}}=0$ otherwise (no change or decrease in $\mathrm{P}_{\mathrm{ij}}$ ). After that, we performed the statistical analysis with Linear Discriminant Analysis (LDA) [38] and obtained the CPT model. The workflow diagram of theoretical section was presented in Fig. 2. The diagram briefly explains theory processes to develop the CPT model.

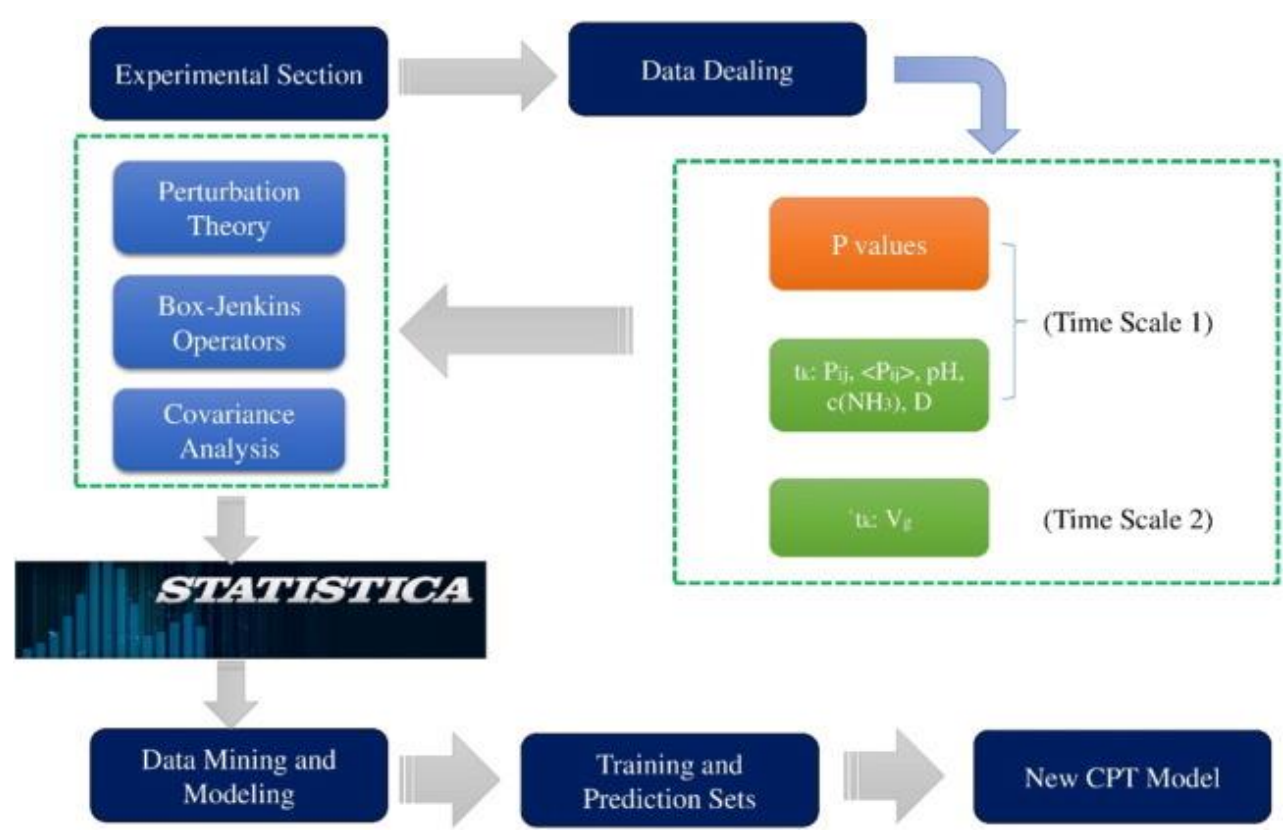

Fig. 2. Flow chart of theoretical section for developing the LDA CPT model (P values represent the cellular permeability, Pij presents each permeability value under various conditions, $\left\langle\mathrm{P}_{\mathrm{ij}}\right\rangle$ means the permeability average values within the same conditions, $\mathrm{c}(\mathrm{NH} 3)=$ ammonia concentration, $\mathrm{D}=$ digestibility of NDF (neutral detergent fibre), $\mathrm{Vg}=$ gas production, $\mathrm{t}_{\mathrm{k}}$ and ${ }^{\mathrm{t}} \mathrm{t}$ represent the two different time scales and CPT $=$ Covariance Perturbation Theory). 


\section{Results and discussion}

\subsection{Cell membrane permeability}

In this study, the experimental results of $\mathrm{P}$ in time scale $\left(t_{k}\right)$ were presented in Table 1 . The values of $\mathrm{P}$ were changed under the different combinatorial conditions of ST and SSA in the time scale $\left(t_{k}\right)$. In general, all the factors (ST, SSA and time) were contributed to the variation of $\mathrm{P}$ values from the analysis and the original data of present work. For instance, the P value was higher for ST at 43 and $46 \mathrm{mN} / \mathrm{m}$ compared to ST at $36 \mathrm{mN} / \mathrm{m}$. The $\mathrm{P}$ values also varied with the time scale $\left(\mathrm{t}_{\mathrm{k}}\right)$. The $\mathrm{P}$ value was greater for $\mathrm{SSA}$ at $4.44 \mathrm{~m}^{2} / \mathrm{g}$ than that of $3.37 \mathrm{~m}^{2} / \mathrm{g}$ as the time from $12 \mathrm{~h}$ to $24 \mathrm{~h}$. The treatment of $\mathrm{ST}=36 \mathrm{mN} / \mathrm{m}$, the $\mathrm{P}$ value was decreased from 6 to $12 \mathrm{~h}$.

Table 1. The cell membrane permeability values of ruminal microbes in the time scale of $t_{k}$.

\begin{tabular}{|c|c|c|c|c|c|c|c|}
\hline \multicolumn{2}{|c|}{ Experimental treatments ${ }^{\mathrm{a}}$} & \multicolumn{6}{|c|}{ The experimental results of $P$ in the time scale of $t_{k}{ }^{b}$} \\
\hline $\operatorname{SSA}\left(\mathrm{m}^{2} / \mathrm{g}\right)$ & $\mathrm{ST}(\mathrm{mN} / \mathrm{m})$ & h6 & h12 & h24 & h36 & h48 & $\mathrm{h} 72$ \\
\hline \multirow[t]{4}{*}{3.37} & 53.95 & 26.6 & 24.5 & 39.4 & 35.2 & 49.5 & 54.0 \\
\hline & 46.09 & 30.0 & 23.9 & 44.1 & 34.5 & 54.2 & 55.1 \\
\hline & 42.78 & 29.3 & 27.6 & 40.6 & 36.3 & 41.3 & 54.1 \\
\hline & 36.07 & 35.8 & 22.3 & 35.6 & 28.7 & 48.6 & 48.9 \\
\hline \multirow[t]{4}{*}{3.73} & 53.95 & 27.1 & 24.3 & 42.2 & 33.3 & 47.0 & 54.0 \\
\hline & 46.09 & 27.2 & 25.0 & 43.0 & 37.7 & 50.5 & 56.3 \\
\hline & 42.78 & 26.1 & 23.4 & 48.6 & 37.7 & 49.0 & 54.8 \\
\hline & 36.07 & 28.9 & 22.1 & 36.0 & 29.6 & 45.7 & 51.4 \\
\hline \multirow[t]{4}{*}{4.44} & 53.95 & 27.7 & 25.6 & 43.4 & 39.9 & 48.6 & 59.0 \\
\hline & 46.09 & 28.8 & 22.2 & 44.6 & 39.6 & 50.0 & 56.5 \\
\hline & 42.78 & 24.5 & 31.3 & 48.3 & 38.6 & 50.6 & 53.5 \\
\hline & 36.07 & 28.8 & 25.5 & 38.2 & 35.5 & 45.4 & 50.7 \\
\hline
\end{tabular}

${ }^{a}$ SSA represents specific surface area $\left(\mathrm{m}^{2} / \mathrm{g}\right)$; ST represents surface tension $(\mathrm{mN} / \mathrm{m})$.

${ }^{\mathrm{b}} 6 \mathrm{~h}, 12 \mathrm{~h}, 24 \mathrm{~h}, 36 \mathrm{~h}, 48 \mathrm{~h}$ and $72 \mathrm{~h}$ mean the mimic in vitro fermentation hours, respectively.

The ST of rumen fluid decreased by supplying exogenous non-ionic surfactant, and a moderate decreasing of ST could increase P of microbe which was noted in present study. Ye et al., [39] also found that the $\mathrm{P}$ of Staphylococcus aureus and Bacillus subtillis increased with the concentrations of octadecanoyl acetal sodium sulfite which decreased the ST of liquid media. In addition, the high P values in cellular organisms may be beneficial to the release of enzymes from intracellular to extracellular. Nakamura et al., [40] reported that the changes in $\mathrm{P}$ of hepatocytes could result in a significant leakage of enzymes from the cells. Wang et al., [41] found that the extracellular enzymatic activity of laccase, lignin peroxidase and manganese peroxidase of Phanerochaete chrysosporium was firstly increased as the strains were exposed to either direct current or alternating current, and accompanied increases in cellular permeability.

\subsection{CPT model for cell membrane permeability}

In this work we reported the experimental determination of cell membrane permeability and in a previous work we published the experimental valuables of variables like $\mathrm{pH}, \mathrm{c}\left(\mathrm{NH}_{3}\right), \mathrm{D}$, and $\mathrm{V}_{\mathrm{g}}$ measured on the same fermentation system with different time scales. This opens a door to the development of general predictive models. In fact, the researchers are looking for a connection between different fermentation systems and replace the traditional partial research works with the integral ecosystem to obtain more information. However, such is a problem that nearly every scientist faces when combining 
many diverse experimental conditions in an integral ecosystem. In doing so, we proposed to use Covariance Perturbation Theory on the situation of dual-time scales to develop theoretical models to reduce the deviation of different conditions on the properties from experimental results. In this sense, we decided to develop for the first time one unified CPT model that is able to predict all these properties (cell membrane permeability and fermentation performances or variables) with a single theoretical model. The CPT model proposed here is able to predict with reasonable accuracy the value of output properties of cell membrane permeability obtained after perturbations on the experimental conditions. The dataset was composited of 77, 871 cases $\left(i^{\text {th }}\right)$ for this new model. The best CPT model developed with this algorithm was the following, the parameters of this new model are presented in Table 2.

$$
\begin{gathered}
{ }^{0} \mathrm{f}\left(\Delta \mathrm{P}_{\mathrm{ij}}>0\right)_{\text {pred }}=0.820670-0.001283 \cdot{ }^{1} \mathrm{f}\left(\mathrm{P}_{\mathrm{j}}\right) \cdot \mathrm{t}_{\mathrm{k}} \\
+0.003199 \cdot \mathrm{ST}\left(\mathrm{t}_{\mathrm{k}}\right) \cdot \Delta \mathrm{D}\left(\mathrm{t}_{/ \mathrm{k}}\right)+0.004033 \cdot \Delta \mathrm{c}_{\mathrm{NH}_{3}}\left(\mathrm{t}_{\mathrm{k}}\right) \cdot \mathrm{t}_{\mathrm{k}} \\
-0.003349 \cdot \mathrm{ST}\left(\mathrm{t}_{\mathrm{k}}\right) \cdot \Delta \mathrm{c}_{\mathrm{NH}_{3}}\left(\mathrm{t}_{\mathrm{k}}\right)-0.138611 \cdot \Delta \mathrm{c}_{\mathrm{NH}_{3}}\left(\mathrm{t}_{\mathrm{k}}\right) \cdot \Delta \mathrm{pH}\left(\mathrm{t}_{\mathrm{k}}\right) \\
+0.095564 \cdot \Delta \mathrm{c}_{\mathrm{APG}}\left({ }^{\prime} \mathrm{t}_{\mathrm{k}}\right) \cdot \Delta \mathrm{Vg}\left({ }^{\prime} \mathrm{t}_{\mathrm{k}}\right) \\
\mathrm{N}=77871 \mathrm{Rc}=0.78 \mathrm{~F}=55167.5 \mathrm{p}<0.001
\end{gathered}
$$

\begin{tabular}{|c|c|c|c|c|}
\hline \multirow{2}{*}{ Data sub-set ${ }^{\mathrm{a}}$} & \multicolumn{2}{|c|}{ Prediction cases ${ }^{\mathrm{b}}$} & \multirow{2}{*}{ Statistical parameters ${ }^{\mathrm{c}}$} & \multirow{2}{*}{ Prediction rates } \\
\hline & $\mathrm{n}\left(\Delta \mathrm{P}_{\mathrm{ij}}>0\right)$ & $\mathrm{n}\left(\Delta \mathrm{P}_{\mathrm{ij}}<=0\right)$ & & \\
\hline \multicolumn{5}{|c|}{ Training dataset } \\
\hline $\mathrm{n}\left(\Delta \mathrm{P}_{\mathrm{ij}}>0\right)$ & 25,903 & 3781 & Specificity (Sp) & 0.873 \\
\hline \multirow[t]{2}{*}{$\mathrm{n}\left(\Delta \mathrm{P}_{\mathrm{ij}}<=0\right)$} & 2374 & 26,346 & Sensitivity (Sn) & 0.917 \\
\hline & & & Accuracy (Ac) & 0.895 \\
\hline \multicolumn{5}{|c|}{ Validation dataset } \\
\hline $\mathrm{n}\left(\Delta \mathrm{P}_{\mathrm{ij}}>0\right)$ & 8673 & 1242 & Specificity (Sp) & 0.875 \\
\hline \multirow[t]{2}{*}{$\mathrm{n}\left(\Delta \mathrm{P}_{\mathrm{ij}}<=0\right)$} & 833 & 8720 & Sensitivity (Sn) & 0.913 \\
\hline & & & Accuracy (Ac) & 0.893 \\
\hline
\end{tabular}

Table 2. Results of the CPT model for the perturbation of cell membrane permeability in vitro fermentation performance.

${ }^{a}$ The data sub-set was separated by a random training/validation $(\mathrm{t} / \mathrm{v})$ rate as $3: 1$.

${ }^{b} \mathrm{n}\left(\Delta \mathrm{P}_{\mathrm{ij}}>0\right)$ means the $\mathrm{P}_{\mathrm{ij}}$ value was greater than average $\left\langle\mathrm{P}_{\mathrm{j}}>\right.$, otherwise as $\mathrm{n}\left(\Delta \mathrm{P}_{\mathrm{ij}}<=0\right)$.

${ }^{c}$ The statistical parameters used to evaluate the performance of new model are specificity (Sp), sensitivity (Sn), accuracy (Ac), and Matthews correlation coefficient (MCC). Among, the values of MCC are 0.78 and 0.79 for training and validation sub-datasets.

The output function ${ }^{0} f\left(\Delta \mathrm{P}_{\mathrm{ij}}>0\right)_{\text {pred }}$ is one score function that quantifies the numerical values as the changes of cell membrane permeability $\Delta \mathrm{P}_{\mathrm{ij}}>0, \mathrm{P}_{\mathrm{ij}}$ are greater than average, under the condition of experimental variables $\mathrm{V}_{\mathrm{q}}\left(\mathrm{t}_{\mathrm{k}}\right)$ for $\mathrm{i}^{\text {th }}$ cases (perturbations). The statistical parameters used for estimating the model in present study are specificity, sensitivity, and accuracy as well as the Matthews correlation coefficient (MCC) [42]. This new model developed is able to predict the effects of perturbations under the experimental conditions or variables $\mathrm{V}_{\mathrm{q}}\left(\mathrm{t}_{\mathrm{k}}\right)$ over cell membrane permeability property of ruminal microbes with sensitivity, specificity, and accuracy of $>0.89$, and MCC $>0.78$ for a dataset with 77,871 cases. On the view of statistical, these predicting performances of this new model are considered good for any LDA model.

The new CPT model obtained in present studyshowed that both of two time series $\left(t_{k}\right.$ and $\left.t_{k}\right)$ were important for prediction model over the changes of cell membrane permeability $\left(\Delta \mathrm{P}_{\mathrm{ij}}\right)$. However, not all types of variables mentioned previously entered the CPT model in present study. For instance, the variable terms like single variables $\mathrm{V}_{\mathrm{q}}\left(\mathrm{t}_{\mathrm{k}}\right)$, cross-product of single variables $\mathrm{V}_{\mathrm{q}}\left(\mathrm{t}_{\mathrm{k}}\right) \cdot \mathrm{V}_{\mathrm{q}_{\mathrm{q}}}\left(\mathrm{t}_{\mathrm{k}}\right)$, single moving average $\Delta \mathrm{V}_{\mathrm{q}}\left(\mathrm{t}_{\mathrm{k}}\right)=\mathrm{V}_{\mathrm{q}}\left(\mathrm{t}_{\mathrm{k}}\right)-\left\langle\mathrm{V}_{\mathrm{q}}\left(\mathrm{t}_{\mathrm{k}}\right)\right\rangle$, and cross-covariance terms $\Delta \mathrm{V}_{\mathrm{q}}\left(\mathrm{t}_{\mathrm{k}}\right) \cdot \Delta \mathrm{V}_{{ }_{\mathrm{q}}}\left(\mathrm{t}_{\mathrm{k}}\right)$ were not mentioned in the new CPT model. It implies that the interaction of different type variables terms like $\Delta \mathrm{V}_{\mathrm{q}}\left(\mathrm{t}_{\mathrm{k}}\right) \cdot \Delta \mathrm{V}_{\mathrm{q}}^{\prime}\left(\mathrm{t}_{\mathrm{k}}\right)$ and $\mathrm{V}_{\mathrm{q}}\left(\mathrm{t}_{\mathrm{k}}\right) \cdot \Delta \mathrm{V}_{\mathrm{q}}^{\prime}\left(\mathrm{t}_{\mathrm{k}}\right)$ rather than the single variables $\mathrm{V}_{\mathrm{q}}\left(\mathrm{t}_{\mathrm{k}}\right)$ or cross-product of single variables $\mathrm{V}_{\mathrm{q}}\left(\mathrm{t}_{\mathrm{k}}\right) \cdot \mathrm{V}_{\mathrm{q}}\left(\mathrm{t}_{\mathrm{k}}\right)$ is vital in the variations of cell membrane permeability $\Delta \mathrm{P}_{\mathrm{ij}}$. On the other hand, the experimental input conditions or variables used for developing the $\mathrm{CPT}$ models, like $\mathrm{c}\left(\mathrm{NH}_{3}\right), \mathrm{pH}$ values, digestibility and gas production, were vital in this CPT model. 


\subsection{CPT model simulation of cell permeability}

In here, we would like to illustrate the use of this new CPT model with the numerical simulation of the effects of perturbations over $\Delta \mathrm{P}_{\mathrm{ij}}$. In this section, we calculated the values of output ${ }^{0} f\left(\Delta \mathrm{P}_{\mathrm{ij}}>0\right)_{\text {pred }}$ of the new CPT model obtained in the previous section. All the predicted values of ${ }^{0} f\left(\Delta \mathrm{P}_{\mathrm{ij}}>0\right)_{\text {pred }}$ are in the range -2 to 2 . After that, we used these output calculated values combined with some experimental variables used as input variables to reflect the relationship of the changes of cellular membrane permeability $\Delta \mathrm{P}_{\mathrm{ij}}$ with $\mathrm{c}\left(\mathrm{NH}_{3}\right), \mathrm{D}$, and $\mathrm{V}_{\mathrm{g}}$. The correlation changes were showed in Fig. 3 .

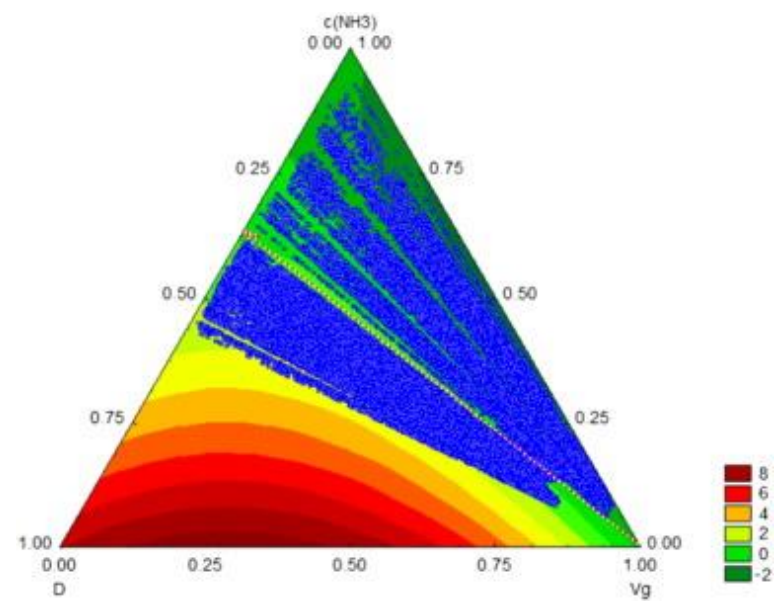

Fig. 3. Ternary diagram for cell membrane permeability changes; $\Delta \mathrm{P}_{\mathrm{ij}} v s$. $\mathrm{c}\left(\mathrm{NH}_{3}\right), \mathrm{D}$, and $\mathrm{V}_{\mathrm{g}}$.

In ternary plot, every point represents a different composition of the three components. The concentration of each species is $100 \%$ or 1 (pure phase) in each corner of the triangle, and $0 \%$ or 0 at the line opposite to it [43]. In our case, the different types of $\Delta \mathrm{P}_{\mathrm{ij}}$ were presented in Fig. 3 individually. When $\Delta \mathrm{P}_{\mathrm{ij}}>0$, the points were appeared in the bigger value side of $\mathrm{D}$ (the triangle corner of $\mathrm{D}$ ), whereas $\Delta \mathrm{P}_{\mathrm{ij}}<=0$ were appeared in opposite to it. All the $\Delta \mathrm{P}_{\mathrm{ij}}>0$, and $\Delta \mathrm{P}_{\mathrm{ij}}<=0$ cases were separated mechanically by a red dotted line (Fig. 3). In addition, the variation values of cell membrane permeability $\Delta \mathrm{P}_{\mathrm{ij}}$ were decreased with the increasing of NDF digestibility, it implies that the ruminal microbes have strong cell permeability in the initiation of metabolism processes. In other words, it means when the value of NDF digestibility is small, it implies that the cell membrane permeability value $>$ the average, whereas the opposite. As in the previous work, the cell membrane permeability or absorption is modulated by factors such as intestinal lumen osmolality and the interaction with mediated nutrients uptake [44] or other exogenous substances [45]. In addition, in real fermentation environment, gas production was changed with different conditions of ST and SSA. However, the predicted values of cell membrane permeability did not show a strong correlation with gas production but increased with the concentration levels of ammonia nitrogen in this simulation model.

\section{Conclusions}

In this work, we presented a new computational method for predicting variations on cell membrane permeability, an important parameter in microbiome. For this purpose, we developed a model that used the experimental parameters to predict the cell membrane permeability. It combines the ideas of Covariance and Cross-covariance analysis, Perturbation Theory, and Time Series Analysis. We show that this CPT model has a good quality to predict the cell permeability with the performance of sensitivity, specificity and accuracy of $>0.89$, and $\mathrm{MCC}>0.78$ for 77,781 perturbation cases in training and validation series. With this simulation model, we can also predict the values of different experimental variables that were not experimentally measured. In final, we also reported a simulation of ternary phase diagram with the predicted values of cell permeability at different experimental conditions. 


\section{Conflict of interest}

The authors declare no competing financial interest.

\section{Acknowledgements}

This project was partially supported by the grants from the National Natural Science Foundation of China (Grant No. 31172234), the Chinese Academy of Science and Technology Strategic Pilot Project (Grant No. XDA05020700) and Hunan Provincial Natural Science Foundation of China (Grant No. 12JJ3015). This work was also supported by the "Galician Network for Colorectal Cancer Research (REGICC)" (Ref. R2014/039), funded by the Xunta de Galicia, by "Collaborative Project on Medical Informatics (CIMED)" PI13/00280.

\section{References}

[1]. O.S. Ostroumova, S.S. Efimova, V.V. Malev. Modifiers of membrane dipole potentials as tools for investigating ion channel formation and functioning. Int. Rev. Cell Mol. Biol., 315 (2015), pp. 245-297.

[2]. D. Soto, N. Comes, E. Ferrer, M. Morales, A. Escalada, J. Pales, C. Solsona, A. Gual, X. Gasull. Modulation of aqueous humor outflow by ionic mechanisms involved in trabecular meshwork cell volume regulation. Invest. Ophthalmol. Vis. Sci., 45 (2004), pp. 3650-3661.

[3]. C.M. Waters, M.R. Glucksberg, N. Depaola, J. Chang, J.B. Grotberg. Shear stress alters pleural mesothelial cell permeability in culture. J. Appl. Physiol., 81 (1996) (1985), pp. 448-458.

[4]. D.J. Welling, L.W. Welling. Cell shape as an indicator of volume reabsorption in proximal nephron. Fed. Proc. 38 (1979), pp. 121-127.

[5]. P. Suomalainen, C. Johans, T. Soderlund, P.K. Kinnunen. Surface activity profiling of drugs applied to the prediction of blood-brain barrier permeability. J. Med. Chem., 47 (2004), pp. 1783-1788.

[6]. J.A. Nicolazzo, B.L. Reed, B.C. Finnin. Assessment of the effects of sodium dodecyl sulfate on the buccal permeability of caffeine and estradiol. J. Pharm. Sci., 93 (2004), pp. 431-440.

[7]. Y. Liu, L.M. Camacho, S. Tang, Z. Tan, A.Z.M. Salem. Advances in nutritional manipulation rumen functions of surfactants. Afr. J. Microbiol. Res., 7 (2013), pp. 1451-1458.

[8]. Y. Liu, S. Tang, Z. Tan. Research progress on using surfactants to regulating rumen function. Genomics Appl. Biol., 31 (2012), pp. 197-204 (in Chinese).

[9]. H. Leontiadou, A.E. Mark, S.J. Marrink. Molecular dynamics simulations of hydrophilic pores in lipid bilayers. Biophys. J., 86 (2004), pp. 2156-2164.

[10]. Y. Liu, T. Ran, Z.-1. Tan, S.-x. Tang, P.-p. Wang. Effects of surface tension and specific surface areas on in vitro fermentation of fiber. Acta Vet. Zootech. Sin., 44 (2013), pp. 901-910 (in Chinese).

[11]. M.R. Spiegel, J.J. Schiller, R.A. Srinivasan. Schaum's Outline of Probability and Statistics. (fourth ed.)McGraw-Hill, New York, Chicago, San Francisco, Lisbon, London, Madrid, Mexico City, Milan, New Delhi, San Juan, Seoul, Singapore, Sydney, Toronto (2013).

[12]. W. Li, W.M. Doyon, J.A. Dani. Acute in vivo nicotine administration enhances synchrony among dopamine neurons. Biochem. Pharmacol., 82 (2011), pp. 977-983.

[13]. X. Xiao, P. Wang, K.C. Chou. iNR-PhysChem: a sequence-based predictor for identifying nuclear receptors and their subfamilies via physical-chemical property matrix. PLoS One, 7 (2012), Article e30869.

[14]. I.A. Doytchinova, D.R. Flower. VaxiJen: a server for prediction of protective antigens, tumour antigens and subunit vaccines. BMC Bioinform., 8 (2007), p. 4.

[15]. X. Liu, L. Zhao, Q. Dong. Protein remote homology detection based on auto-cross covariance transformation. Comput. Biol. Med., 41 (2011), pp. 640-647.

[16]. S. Wold. Chemometrics; what do we mean with it, and what do we want from it?. Chemom. Intell. Lab. Syst., 30 (1995), pp. 109-115.

[17]. A. Conesa, J.M. Prats-Montalbán, S. Tarazona, M.J. Nueda, A. Ferrer. A multiway approach to data integration in systems biology based on Tucker3 and N-PLS. Chemom. Intell. Lab. Syst., 104 (2010), pp. 101-111.

[18]. L. Zhang, X. Han, Z. Li, R. Liu, W. Xu, C. Tang, X. Wang, H. Xiao. Metabolomics research on time-selected combination of Liuwei Dihuang and Jinkui Shenqi pills in treating kidney deficiency and aging by chemometric methods. Chemom. Intell. Lab. Syst., 130 (2014), pp. 50-57.

[19]. Y. Liu, C.G. Peñuelas-Rivas, E. Tenorio-Borroto, M. Rivas-Guevara, G. Buendía-Rodríguez, Z. Tan, H. González-Díaz. Chemometric approach to fatty acid metabolism-distribution networks and methane production in ruminal microbiome. Chemom. Intell. Lab. Syst., 151 (2016), pp. 1-8.

[20]. H. Gonzalez-Diaz, S. Arrasate, A. Gomez-SanJuan, N. Sotomayor, E. Lete, L. Besada-Porto, J.M. Ruso. General theory for multiple input-output perturbations in complex molecular systems. 1. Linear QSPR electronegativity models in physical, organic, and medicinal chemistry. Curr. Top. Med. Chem., 13 (2013) (17131741).

[21]. V.V. Kleandrova, F. Luan, H. Gonzalez-Diaz, J.M. Ruso, A. Speck-Planche, M.N. Cordeiro. Computational tool for risk assessment of nanomaterials: novel QSTR-perturbation model for simultaneous prediction of ecotoxicity and cytotoxicity of uncoated and coated nanoparticles under multiple experimental conditions. Environ. Sci. Technol., 48 (2014), pp. 14686-14694. 
[22]. H. Gonzalez-Diaz, S. Arrasate, A.G. Juan, N. Sotomayor, E. Lete, A. Speck-Planche, J.M. Ruso, F. Luan, M.N. Cordeiro. Matrix trace operators: from spectral moments of molecular graphs and complex networks to perturbations in synthetic reactions, micelle nanoparticles, and drug ADME processes. Curr. Drug Metab., 15 (2014), pp. 470-488.

[23]. V.V. Kleandrova, F. Luan, H. Gonzalez-Diaz, J.M. Ruso, A. Melo, A. Speck-Planche, M.N. Cordeiro. Computational ecotoxicology: simultaneous prediction of ecotoxic effects of nanoparticles under different experimental conditions. Environ. Int., 73 (2014), pp. 288-294.

[24]. F. Luan, V.V. Kleandrova, H. Gonzalez-Diaz, J.M. Ruso, A. Melo, A. Speck-Planche, M.N. Cordeiro. Computer-aided nanotoxicology: assessing cytotoxicity of nanoparticles under diverse experimental conditions by using a novel QSTR-perturbation approach. Nanoscale, 6 (2014), pp. 10623-10630.

[25]. Y. Liu, G. Buendia-Rodriguez, C.G. Penuelas-Rivas, Z. Tan, M. Rivas-Guevara, E. Tenorio-Borroto, C.R. Munteanu, A. Pazos, H. Gonzalez-Diaz. Experimental and computational studies of fatty acid distribution networks. Mol. BioSyst., 11 (2015), pp. 2964-2977.

[26]. P.V. Messina, J.M. Besada-Porto, H. González-Díaz, J.M. Ruso. Self-assembled binary nanoscale systems: multioutput model with lfer-covariance perturbation theory and an experimental-computational study of nagdcddab micelles. Langmuir (2015).

[27]. J.T. Blake, R.S. Allen, N.L. Jacobson. The influence of various factors on surface tension and $\mathrm{pH}$ of rumen fluid. J. Anim. Sci., 16 (1957), pp. 190-200.

[28]. P.J. Van Soest, J.B. Robertson, B.A. Lewis. Methods for dietary fiber, neutral detergent fiber, and nonstarch polysaccharides in relation to animal nutrition. J. Dairy Sci., 74 (1991), pp. 3583-3597.

[29]. J.S. Li, Z.W. Jiang. Distribution of food particles with different size in the digestive tract in Mongolian gazelle. Acta Zool. Sin., 47 (2001), pp. 488-494.

[30]. Y.G. Zhen, L. Ma. Comparative study on fibre digestion and rumen digestion dynamics in small ruminants fed various low-quality roughage. J. Jilin Agric. Univ., 20 (1998), pp. 66-72.

[31]. X.G. Zhao, M. Wang, Z.L. Tan, S.X. Tang, Z.H. Sun, C.S. Zhou, X.F. Han. Effects of rice straw particle size on chewing activity, feed intake, rumen fermentation and digestion in goats. Asian Aust. J. Anim. Sci, 22 (2009), pp. $1256-1266$.

[32]. S. Brunauer, P.H. Emmett, E. Teller. Adsorption of gases in multimolecular layers. J. Am. Chem. Soc., 60 (1938), pp. 309-319.

[33]. S. Tang, Z. Tan, C. Zhou, H. Jiang, Y. Jiang, L. Sheng. A comparison of in vitro fermentation characteristics of different botanical fractions of mature maize stover. J. Anim. Feed Sci., 15 (2006), pp. 505-515.

[34]. S.X. Tang, G.O. Tayo, Z.L. Tan, Z.H. Sun, L.X. Shen, C.S. Zhou, W.J. Xiao, G.P. Ren, X.F. Han, S.B. Shen . Effects of yeast culture and fibrolytic enzyme supplementation on in vitro fermentation characteristics of lowquality cereal straws. J. Anim. Sci., 86 (2008), pp. 1164-1172.

[35]. F.Y. Wang, C.C. Miao, H.L. Han, W.B. Jin, Z. Liu. Effect of electric field on cell growth, permeability and extracellular enzymatic reactions of phanerochaete chrysosporium. Chin. J. Process. Eng., 7 (2007), pp. 385-389.

[36]. Y. Liu, S. Tang. Full Dataset for Experimental and Chemometrics Study of Cell Membrane Permeability. Figshare (2015).

[37]. T. Hill, P. Lewicki. Statistics Methods and Applications. A Comprehensive Reference for Science. Industry and Data Mining, StatSoft, Tulsa (2006).

[38]. R.A. Fisher. The use of multiple measurements. In taxonomic problems. Ann. Eugenics, 7 (1936), pp. 179-188.

[39]. X. Ye, X. Li, L. Yuan, H. He. Effect of the surface activity on the antibacterial activity of octadecanoyl acetal sodium sulfite series. Colloids Surf. A Physicochem. Eng. Asp., 268 (2005), pp. 85-89.

[40]. T. Nakamura, T. Fujii, A. Ichihara. Enzyme leakage due to change of membrane permeability of primary cultured rat hepatocytes treated with various hepatotoxins and its prevention by glycyrrhizin. Cell Biol. Toxicol., 1 (1985), pp. 285-295.

[41]. F.-y. Wang, C.-c. Miao, H.-1. Han, W.-b. Jin, Z. Liu. Effect of electric field on cell growth, permeability and extracellular enzymatic reactions of phanerochaete chrysosporium. Chin. J. Process Eng. (2007), pp. 385-389.

[42]. G. Jurman, S. Riccadonna, C. Furlanello. A comparison of MCC and CEN error measures in multi-class prediction. PLoS One, 7 (2012), Article e41882.

[43]. W. Vaughan. Ternary plots. wvaughan.org (2010).

[44]. K.R. Napier, C. Purchase, T.J. McWhorter, S.W. Nicolson, P.A. Fleming. The sweet life: diet sugar concentration influences paracellular glucose absorption. Biol. Lett., 4 (2008), pp. 530-533.

[45]. J.M. Stewart, D.S. Schultz, O.T. Lee, M.L. Trinidad. Exogenous collagen cross-linking reduces scleral permeability: modeling the effects of age-related cross-link accumulation. Invest. Ophthalmol. Vis. Sci., 50 (2009), pp. 352-357. 